\title{
Coopération entre FMH Encaissement Services SA et Encath SA à Bienne
}

La coopération entre FMH Encaissement Services SA et le service d'encaissement Encath SA (INKAS / Service d'encaissement pour médecins et dentistes) a commencé en mars 2006. Cette décision a été bien accueillie par les médecins et notre clientèle augmente de façon réjouissante. Ce regroupement de deux unités opérationnelles au siège de l'INKAS à Bienne depuis mai 2006 permet de gérer l'ensemble de la clientèle sur un seul site avec des synergies utilisées de manière optimale.

Nouveau modèle commercial et conditions améliorées Les réactions de nos «anciens» clients ont été très positives. Les nouvelles conditions mises en place sont très appréciées. Le risque financier est désormais réduit à un minimum pour le donneur $d^{\prime}$ 'ordre et il est identique aux coûts d'une solution obtenue individuellement. Nos clients s'informent régulièrement des cas d'encaissements en cours ou déjà réglés en consultant notre site internet «my.inkas.ch» dont l'accès est protégé par un mot de passe.

\section{Nouveaux bureaux}

Cette coopération a également permis à nos collaboratrices et collaborateurs, au nombre de 30 environ, d'occuper de nouveaux locaux au centre ville, aménagés de façon agréable et équipés des toutes nouvelles technologies de l'informatique, ce qui garantit un service à la clientèle couronné de succès.

\section{Compétences et savoir-faire}

En notre qualité d'entreprise leader d'encaissement pour médecins et dentistes, nous mettons à votre disposition l'expérience que nous avons acquise dans l'encaissement d'honoraires impayées. Nous effectuons dans votre intérêt toutes les investigations nécessaires, vous conseillons de manière individuelle et nous occupons aussi de l'administration des actes de défaut de biens. Veuillez nous envoyer votre copie de facture ou votre dernier rappel au débiteur et nous réglerons le reste pour vous. Nos clients sont satisfaits et c'est notre meilleure publicité.

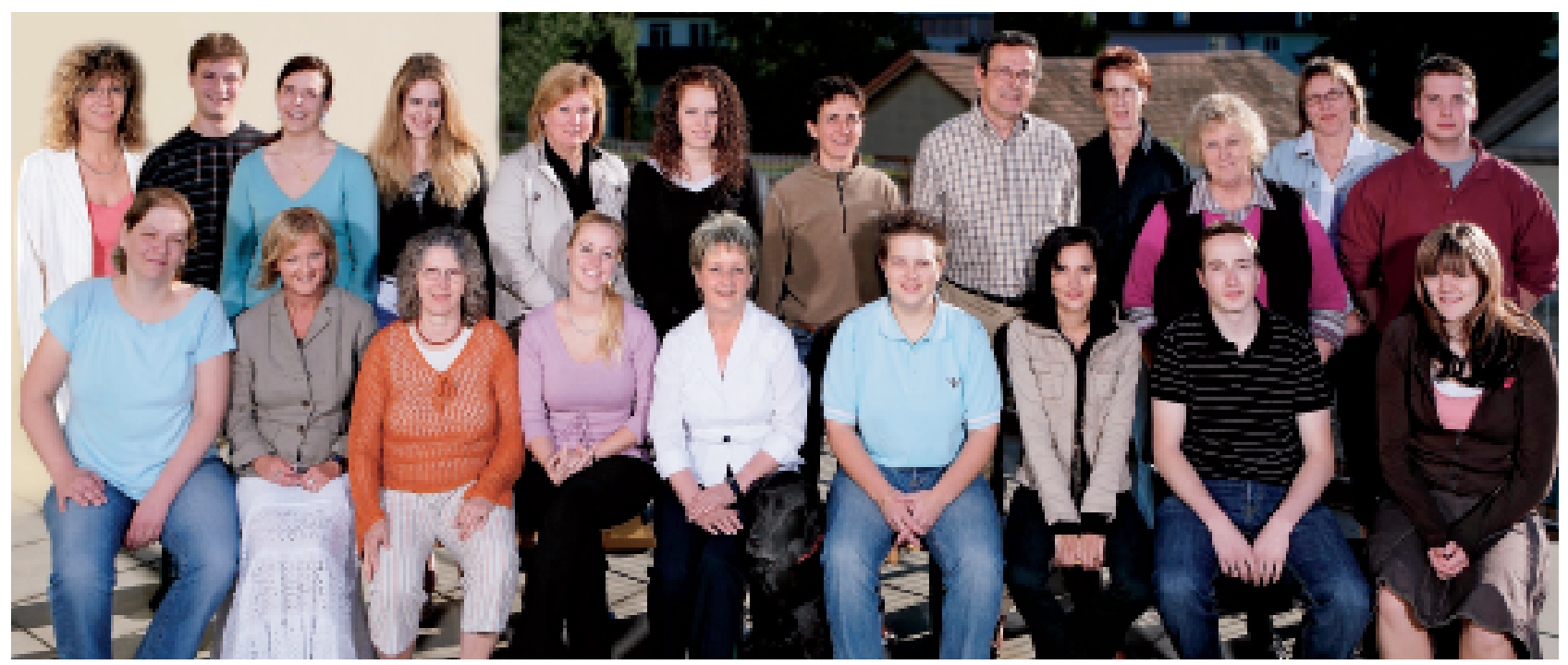

Equipe FMH Encaissement Services / INKAS

\section{Coupon-réponse}

Prière d'envoyer ou de faxer à: 0323443966

Prénom/ Nom

Adresse

NPA/ Localité

Tél. privé/professionnel

Meilleur moment

pour un appel

Je désire un entretien-conseil personnel.

O Veuillez $\mathrm{m}^{\prime}$ envoyer votre documentation relative à l'encaissement.

\section{FMH ENCAISSEMENT}

Service d'encaissement Encath SA

Service de coordination

Case postale $800 \square 2501$ Bienne

Tél. 0323443969 " Fax 0323443966

mail@fmhencaissement.ch $\square$ www.fmhencaissement.ch 